\title{
Epidemiological and Clinical Profile of COVID-19 in Nepali Children: An Initial Experience
}

\author{
Arun K Sharma ${ }^{1}$, Ram H Chapagain ${ }^{1}$, Krishna P Bista ${ }^{1}$, Roma Bohara ${ }^{2}$, Bharat \\ Chand $^{2}$, Nanda K Chaudhary ${ }^{2}$, Pradip Mishra ${ }^{2}$, Sandeep Shrestha ${ }^{2}$, Netra Rana ${ }^{2}$, \\ Jamun Singh ${ }^{2}$, Yuba Nidhi Baseula ${ }^{2}$, Yog Raj Sharma ${ }^{2}$, Samana Sharma ${ }^{2}$ and Sunita \\ Ghimire $^{2}$
}

${ }^{1}$ Nepal Paediatric Society Secretariat

${ }^{2}$ Government of Nepal designated COVID centre

\author{
Correspondence: \\ Arun Kumar Sharma \\ General Secretary, \\ Nepal Paediatric Society \\ Email: docarunsharma@hotmail.com
}

DOI: $10.3126 /$ jnps.v40i3.32438

Submitted on: $2020-10-02$

Accepted on: 2020-10-29

Acknowledgements: None

Funding: Nil

Conflict of Interest: None declared

Permission from IRB: Yes

To cite this article: Sharma $A K$, Chapagain RH, Bista KP, Bohara R, Chand B, Chaudhary NK, Mishra P, Shrestha S, Rana N, Singh J, Baseula YN, Sharma YR, Sharma S, Ghimire S. Epidemiological and clinical profile of COVID-19 in nepali children: An initial experience. J Nepal Paediatr Soc. 2020;40(3):202-9.

\section{ABSTRACT}

Introduction: COVID-19 has spread all around the world with huge toll of human lives and suffering since it evolved in China. Nepal had slow rise in morbidity due to COVID 19 in early days but has been gripped by the pandemic's exponential growth lately. This study was conducted with the aim to describe the clinical and epidemiological features of Nepali children in early phase of the pandemic.

Methods: This was an observational study conducted at 11 COVID care centres designated by the Government of Nepal with availability of supervision by paediatricians between January and August 2020 in children under 18 years of age diagnosed with COVID 19. Data was collected based on definitions outlined in data collection resources available at WHO-ISARIC Global COVID-19 clinical resources platform and analysed.

Results: One hundred and twenty one children diagnosed with COVID 19 who presented to the designated centres were enrolled. Majority of children (83.4\%) were identified as a part of contact tracing, $28.1 \%$ had an identified contact to a person with COVID 19 prior to their diagnosis and $20.7 \%$ had another household member diagnosed with COVID 19. The mean age of admitted children was 8.8 years (SD 5.6 years) with the largest proportion being adolescents $(40.5 \%)$. Male $(58.7 \%)$ children were more commonly affected. There were $15(12.4 \%)$ infants and 8 $(6 \%)$ of them were under two months of age. Most children $(87,71.9 \%)$ were asymptomatic, $21(22.3 \%)$ had mild symptoms and six $(4.9 \%)$ had moderately severe symptoms. Fever $(18.2 \%)$ was the most commonly reported symptom. All children were discharged after a median of 14 days of hospitalisation.

Conclusions: Nepali children of all ages are affected by COVID 19 and present with asymptomatic or mildly symptomatic infection. Fever and respiratory symptoms are the most commonly reported symptoms. Most children do not develop complications. Continued surveillance in larger population of children as the pandemic unfolds will generate more stringent observations.

Key words: COVID 19; Nepal; Children

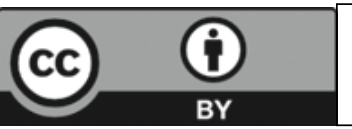

This work is licensed under creative common attribution 3.0 license 


\section{INTRODUCTION}

Since it began in Wuhan in December 2019, Coronavirus disease 2019 (COVID-19), caused by severe acute respiratory syndrome coronavirus 2(SARS-CoV-2), ${ }^{1}$ has created sad public health stories all around the world with more than 34 million cases and over one million deaths. ${ }^{2}$ Nepal reported the first diagnosis of COVID 19 in January 2020. ${ }^{3}$ Although the pandemic evolved slowly in Nepal, there has been recent surge in COVID-19 diagnosis with total cases surpassing 100,000 and more than 500 deaths. Children and adolescents under 20 years of age constituted $8 \%$ of all reported patients. ${ }^{4}$

There has been a growing volume of data focused on COVID-19 from across the world on epidemiological features, clinical manifestations, and transmission patterns. Children constitute a smaller proportion of diagnosed COIVD 19 and majority of childhood disease has been relatively milder as compared to adults in most parts of the world. ${ }^{5}$ Although COVID 19 cases load is growing in Nepal, limited data is available in Nepali children with COVID-19. Smaller number of children was diagnosed with COVID-19 in early months of the pandemic in the country; however the number of cases in children is growing everyday steadily with increasing total case loads in the country.

Early observations in any pandemic of this scale are pivotal to improve the understanding of the locally relevant epidemiological and clinical patterns of the disease to improve early recognition and appropriate management. This article aims to describe the clinical and epidemiological features of paediatric patients seen at different COVID management centres across the country in early phase of the pandemic.

\section{METHODS}

This observational study was conducted at 11 COVID care centres COVID designated hospitals and isolation centers at Janakpur, Birjung, Biratnagar (Eastern Nepal), Nepalgunj, Jumla, Dhangadi, Pokhara, Butwal (Western Nepal), Chitwan, Nuwakot and Kathmandu (Central Nepal)\} distributed across the country between
January and August 2020. The centres were selected from the list of centres designated by Government of Nepal based on availability of paediatricians to oversee patients even if they were not involved in direct patient care. Children under 18 years of age diagnosed with COVID-19 based on positive RT-PCR of nasal / nasopharyngeal swab specimen at designated COVID care areas supervised by paediatricians were considered eligible. During the study period, even asymptomatic children who tested positive for COVID-19 were being admitted as per the prevailing management guidelines of Epidemiology and Disease Control Division of Government of Nepal. Discharge criteria also changed over time. During the study period, patients were being discharged once they were documented to be negative for COVID-19.

De-identified data was collected from participants on rapid-core CRF module developed and standardised by WHO-ISARIC for COVID-19 with some additional epidemiological questions. Data was collected based on definitions outlined in data collection resources available at WHO-ISARIC Global COVID-19 clinical resources platform. ${ }^{6}$ Paediatricians at designated COVID care areas filled up paper based questionnaire forms for patients admitted at the centre they were supervising and electronically transferred to NEPAS office. At NEPAS office, the paper forms were entered into an electronic database in Epi Info $^{\mathrm{TM}}$ software and analysed.

The study protocol was approved by Nepal Health Research Council. Participating institutions agreed to share their data with written declarations. Considering the nature of data collection involving patients with COVID-19 amidst a public health emergency with ongoing national public health response measures to control the outbreak, the ethical review board waived need of a written informed consent. All participants however provided assent for participation in the study.

Children reported with COVID-19 were classified into one of the following categories: ${ }^{7}$

- Asymptomatic infection: without any clinical symptoms and signs 
- Mild: Symptomatic patients meeting WHO case definition for COVID 19 without pneumonia or hypoxia

- Moderate: Pneumonia but no hypoxemia

- Severe: Pneumonia with at least one danger signs or hypoxia

- Critical: ARDS / sepsis / septic shock with evidence of organ dysfunction

Patients were managed based on prevailing national guidelines; laboratory and radiological evaluation were performed only if felt necessary by the treating team based on those guidelines. Accordingly, discharge criteria from hospital during the period of this study was asymptomatic and negative for two nasopharyngeal swabs taken 24 hours apart after day 14 of illness.

The data was analysed and is presented as proportions for participant characteristics. $\chi 2$ tests and Fisher's exact tests were used for categorical variables as appropriate, and the Mann-Whitney U test was used for comparing median values of nonnormally distributed variables. A $p$ value $<0.05$ was considered significant.

\section{RESULTS}

During the study period (at early phase of the pandemic in Nepal) between January and August 2020, 121 children diagnosed with COVID-19 who presented to 11 Government of Nepal designated COVID care centres were included. The epidemiological and demographic profile of the children included in the study is presented in Table 1. Majority of children were identified as a part of contact tracing (83.4\%). Many children (28.1\%) had an identified contact prior to their diagnosis and $20.7 \%$ had another household member diagnosed with COVID-19. The mean age of admitted children was 8.8 years (SD 5.6 years), with a male preponderance $(58.7 \%)$. There were 15 $(12.4 \%)$ infants and eight $(6 \%)$ of them were under two months of age.

Most children had no or only mild symptoms. Clinical characteristics of the study population at the time of presentation are summarised in table 2 . Fever and respiratory symptoms were most common. Anosmia / dysguesia was not reported by
Table 1. Demographic and epidemiological characteristics of study population $(\mathrm{N}=121)$

\begin{tabular}{|c|c|c|}
\hline Patient characteristics & Number & $(\%)$ \\
\hline \multicolumn{3}{|l|}{ Demographic characteristics } \\
\hline Mean age (Years, SD) & 8.8 (SD 5.6) & \\
\hline $\begin{array}{l}\text { Median age (Years, Interquartile } \\
\text { range } 25-75 \text { ) }\end{array}$ & $\begin{array}{l}\text { 9, IQR }(25- \\
75) 4-14\end{array}$ & \\
\hline Range & $\begin{array}{l}7 \text { days to } 18 \\
\text { years }\end{array}$ & \\
\hline \multicolumn{3}{|l|}{ Age groups } \\
\hline Infants & 14 & 11.6 \\
\hline $1-5$ years & 21 & 17.4 \\
\hline $5-10$ years & 37 & 30.6 \\
\hline$>10$ years & 49 & 40.5 \\
\hline Male gender & 71 & 58.7 \\
\hline $\begin{array}{l}\text { Number of members in child's } \\
\text { household, (Median IQR) }\end{array}$ & $\begin{array}{l}5, \mathrm{IQR}(25- \\
75) 4-6\end{array}$ & \\
\hline \multicolumn{3}{|l|}{ Child's ethnic group } \\
\hline Brahman / Chhetri & 24 & 19.8 \\
\hline Tarai / Madhesi & 39 & 32.2 \\
\hline Dalit & 17 & 14 \\
\hline Newar & 9 & 7.4 \\
\hline Janajati & 7 & 5.8 \\
\hline Muslim & 18 & 14.9 \\
\hline Other & 7 & 5.8 \\
\hline \multicolumn{3}{|l|}{$\begin{array}{l}\text { Highest parental education in Father } \\
(\mathrm{N}=101)\end{array}$} \\
\hline No formal schooling & 3 & 3 \\
\hline Primary school & 21 & 20.8 \\
\hline Secondary school & 17 & 16.8 \\
\hline High school & 44 & 43.6 \\
\hline University education & 16 & 15.8 \\
\hline \multicolumn{3}{|l|}{ Highest parental education in mother } \\
\hline No formal schooling & 25 & 24.5 \\
\hline Primary school & 30 & 29.4 \\
\hline Secondary school & 12 & 11.8 \\
\hline High school & 30 & 29.4 \\
\hline University education & 5 & 4.9 \\
\hline \multicolumn{3}{|l|}{ Epidemiological characteristics } \\
\hline \multicolumn{3}{|l|}{ Indication of COVID 19 testing } \\
\hline Suspicion of COVID-19 & 7 & 5.7 \\
\hline Identified at a screening point & 3 & 2.4 \\
\hline Repatriation & 10 & 8.2 \\
\hline \multicolumn{3}{|l|}{ Potential contact of child } \\
\hline $\begin{array}{l}\text { History of recent travel }(<14 \\
\text { days) }\end{array}$ & 24 & 19.8 \\
\hline $\begin{array}{l}\text { History of visit to a healthcare } \\
\text { facility ( }<14 \text { days })\end{array}$ & 9 & 7.4 \\
\hline $\begin{array}{l}\text { Child's family member is a } \\
\text { healthcare worker }\end{array}$ & 7 & 5.8 \\
\hline $\begin{array}{l}\text { Contact with confirmed case } \\
(<14 \text { days })\end{array}$ & 28 & 23.1 \\
\hline
\end{tabular}


Table 2. Clinical characteristics of the study population

\begin{tabular}{|c|c|c|}
\hline Clinical characteristics $(\mathrm{N}=121)$ & Number & $(\%)$ \\
\hline \multicolumn{3}{|l|}{ Symptoms at presentation } \\
\hline Asymptomatic & 87 & 71.9 \\
\hline $\begin{array}{l}\text { Feverish feeling or } \\
\text { measured temperature } \\
>38^{\circ} \mathrm{C}\end{array}$ & 22 & 18.2 \\
\hline Cough & 17 & 14.0 \\
\hline $\begin{array}{l}\text { Dyspnea / Shortness of } \\
\text { breath }\end{array}$ & 5 & 4.1 \\
\hline Sputum / expectoration & 5 & 4.1 \\
\hline Sore throat & 9 & 7.6 \\
\hline Runny nose & 5 & 4.1 \\
\hline Malaise / Fatigue & 4 & 3.3 \\
\hline Myalgia & 1 & 0.8 \\
\hline Headache & 8 & 6.6 \\
\hline Nausea / Vomiting & 5 & 4.1 \\
\hline Abdominal pain & 3 & 2.5 \\
\hline Diarrhea & 3 & 2.5 \\
\hline \multicolumn{3}{|l|}{ Clinical signs at presentation } \\
\hline GCS $15 / 15$ & 121 & $100 \%$ \\
\hline Tachypnea & 7 & 5.8 \\
\hline $\begin{array}{l}\text { Temperature, Median } \\
\text { (IQR } 25-75)\end{array}$ & $\begin{array}{r}37 \\
(37-38)\end{array}$ & \\
\hline $\begin{array}{l}\text { Oxygen saturation, mean } \\
\text { (SD) }\end{array}$ & $\begin{array}{r}97.8(\mathrm{SD} \\
1.6)\end{array}$ & \\
\hline \multicolumn{3}{|l|}{ Pre- existing co-morbid conditions } \\
\hline Pre - existing illness & 5 & 4.1 \\
\hline \multicolumn{3}{|l|}{ Illness severity } \\
\hline Asymptomatic & 87 & 71.9 \\
\hline Mild & 27 & 22.3 \\
\hline Moderate & 6 & 4.9 \\
\hline Severe & 1 & 0.8 \\
\hline Critical & 0 & 0 \\
\hline
\end{tabular}

Laboratory results $(n=22)$, mean (SD)

Hemoglobin g / dL, mean $\quad 11.13 \quad 2.78$ (SD)

$9256 \quad 4004$

Total White-cell count (cells $/ \mathrm{mm}^{3}$ ), mean (SD)

Neutrophil count

Lymphocyte count

Platelet count / cu mm, mean (SD)

220631128435

any patient. Only one patient had moderately severe disease based on illness category with
Table 3. Clinical course and outcome

\begin{tabular}{|lrr|}
\hline Characteristics & Number & $\%$ \\
\hline Clinical course in hospital & & \\
$\quad \begin{array}{l}\text { Received oxygen therapy } \\
\text { Received noninvasive / } \\
\text { invasive ventilation }\end{array}$ & 0 & 0 \\
$\quad \begin{array}{l}\text { Received inotropes } \\
\text { Outcome at discharge }\end{array}$ & 0 & 0 \\
$\quad \begin{array}{l}\text { Discharged alive } \\
\text { Duration of hospital stay, } \\
\text { Median }\end{array}$ & 14 days & \\
\end{tabular}

oxygen saturation of $88 \%$ in presence of respiratory symptoms.

All patients received supportive treatment. Most children did not develop more severe disease or complications related to COVID 19. (Table 3) Only one child who was hypoxic and required oxygen therapy was admitted to HDU based on the hospital policy and recovered with minimal oxygen support. The median duration of hospital stay for these children was 14 days and most children did not require supplemental oxygen therapy or high dependency care. No deaths were reported.

\section{DISCUSSION}

COVID 19 emerged in Wuhan, China in December 2019 and quickly spread all around the world to cause deaths of more than one million people. ${ }^{8}$ Although Nepal reported a first case early in the phase of the pandemic, ${ }^{3}$ only a small number was identified through intensive case finding and contact tracing efforts of the Government of Nepal till end of July 2020. Children under 15 years of age constituted $6.3 \%$ (1477) out of 23,308 patients diagnosed with COVID-19 by the first week of August. ${ }^{9}$ Lately, since August 2020, however, the case count has risen sharply with pandemic reaching the community phase of transmission. Strict lockdown involving the closure of schools and non-essential workplaces, a ban on social gatherings, and severe travel restrictions in the initial days with loosening of these measures over time are the most important reasons for this change in epidemiological trends. This paper presents local 
data on epidemiology, clinical manifestations, and outcomes of children hospitalised with COVID-19 at Government designated centres in Nepal during the early phase of the pandemic. A small number of cases in children required hospitalisation compared to adults during the same period. The number of children affected by COVID-19 in Nepal has expanded exponentially since August $2020 .{ }^{4}$ With changing epidemiological trends, the admission criteria have changed and most children are now being managed in home isolation rather than being admitted to hospital. ${ }^{4}$

This report on initial experience in 121 Nepali children reaffirms the observations made elsewhere in the world. Most children are either asymptomatic $(71.9 \%)$ or mildly symptomatic $(18.2 \%)$ and fever was the most commonly reported symptom. Most children were recognised during contact tracing and screening; patients did not develop any complications during the period of hospitalisation. There were no deaths reported.

This study highlighted that majority of paediatric patients diagnosed with COVID-19 were identified through contact investigation or community tracing. Studies from other parts of the globe have produced similar results and children are not considered the primary drivers of transmission. ${ }^{10} \mathrm{~A}$ household contact as an index case prior to child's diagnosis was identified in $20.8 \%$ of the study population. This result is similar to findings from other countries. ${ }^{10}$

The epidemiological data produced by the Epidemiology and Disease Control Division of Government of Nepal shows that children under 20 years of age constitute about $7.03 \%$ of all confirmed COVID-19 infections in the country. ${ }^{4}$ Pooled analysis of different reports in geographically and ethnically distinct population has identified that approximately $40-45 \%$ of COVID-19 infection is asymptomatic. ${ }^{11,12}$ Although much higher rate of asymptomatic infection has been reported in some parts of the world, ${ }^{13}$ evidence of pre-symptomatic disease in people testing positive by RT-PCR for SARS CoV2 compounds the picture of any point estimate of asymptomatic patients. Many of these asymptomatic patients go on to develop symptoms later. ${ }^{14}$ An even higher proportion of asymptomatic patients in the current study contrasts with these figures. This may partly be related to the study population as only children under 18 years of age were included in this study. The huge proportion of children with asymptomatic SARS-CoV-2 infection compared to adult patients is evident in most published literature. ${ }^{15,16}$ It is still not clear why children's COVID-19 are less severe than adults and may relate to both exposure and host factors. ${ }^{17}$ Routine situation data updates available through national database in Nepal does not include proportion of symptomatic people among all patients diagnosed with COVID-19.

Most children diagnosed with COVID-19 were adolescents. Boys were more frequently diagnosed $(58.7 \%)$ than girls. Available evidence shows that males are slightly more susceptible to SARS-CoV2 infection, present with a more severe disease, and have a worse prognosis. ${ }^{18}$ Older children and adolescents are more commonly affected with COVID-19; in a report from United States on 2572 children, the median age was 11 years and nearly a third of reported paediatric cases (32\%) occurred in children aged $15-17$ years, followed by those in children aged $10-14$ years $(27 \%) .{ }^{19}$

The most common symptom reported among symptomatic children in our study was fever followed by respiratory symptoms. These findings are similar to other reported series..$^{20}$ Pneumonia is the leading infectious cause of death in children younger than five years; SARS - CoV2 preferentially attacks the respiratory tract of both lower and upper airways. However, only a small number of children with COVID-19 in this series actually had pneumonia or more severe illness category. In a large case series from China, more than $90 \%$ of 2,135 children diagnosed with COVID-19 were asymptomatic or had mildmoderate disease; only $5.2 \%$ had severe disease and $0.6 \%$ had critical disease. ${ }^{21}$ However, epidemiological trends in Nepal reported here also represent the fact that in early phase of the pandemic when management algorithms were still being developed, more people identified through contact tracing and screening were admitted rather than illness severity driven hospital admission. 
Additionally, possibilities of a less virulent viral strain causing COVID-19 in circulation, more favourable geographical factors and household environmental condition for Nepali children may also be responsible.

At the time of admission, most children had stable vital signs and mean oxygen saturation was recorded at the same time. Co-morbidities were not commonly associated. Most children remained stable during the period of admission and only one patient required admission to high dependency care based on existing hospital policy for supplemental oxygen. No deaths were reported. Published literature supports that children with COVID-19 rarely have severe or critical illness, and deaths with disease progression among them is extremely low. ${ }^{22}$ Co-morbidities have been particularly important in children requiring intensive care for respiratory, circulatory or neuro-critical care; a report from paediatric intensive care units in US and Canada report that about $83 \%$ of children requiring ICU admissions had significant preexisting co-morbidities. ${ }^{23}$ The profile of children presented in this series is different with most children having asymptomatic or minimally symptomatic illness.

Laboratory results were available for analysis in smaller number of patients and there was no uniform testing guidelines. In this study, most patients had normal routine haematological parameters. Radiography was performed in eight patients only and only two had infiltrates identified in the radiograph. In a meta - analysis of published paediatric literature, serum inflammatory markers, specifically D-dimer, procalcitonin, creatine kinase, and interleukin-6, were found to be consistently abnormal although the authors advised caution till more robust, longitudinal laboratory analyses became available. ${ }^{24}$ Blood counts are usually described to be normal in most patients with neutrophil counts towards the lower side. ${ }^{24}$ Most pediatric patients have normal chest X-rays consistent with the finding that most patients did not present with respiratory symptoms. Number of patients included in this study is very small in size to make good comparison with other studies.
Multi system inflammatory syndrome in children (MIS-C), defined as clinically severe illness requiring hospitalisation with fever, elevated inflammatory markers and multi-system organ dysfunction in the setting of recent SARS $-\mathrm{CoV}-2$ infection in the absence of an alternative likely explanation has been reported in countries with recent surge of COVID-19. ${ }^{25,26}$ In this study, no MIS-C like illness was reported but there may be more of such illness in future with increasing number of children diagnosed with COVID-19.

There are several limitations to generalise the findings of this study. The results of this study narrate the profile of Nepali children identified early in the course of pandemic in the country when the screening, testing and diagnostic guidelines, hospitalisation and discharge criteria and clinical management protocol were constantly evolving and changing. The report is based on small number of patients; clinical and epidemiological characteristics in any population are best described in larger number of patients. All patients were not treated by paediatricians and there was no standard treatment protocol being followed. This study was only conducted in designated COVID care areas and the clinical profile of patients described in this study may not represent general community spectrum of paediatric patients. Although Government had put in a testing guideline in place for all suspected COVID cases, all children may not have undergone the testing. The period of data collection was during the early phase of the pandemic with fewer reported paediatric cases. As the pandemic unfolds, there has been a surge in the number of children diagnosed with COIVD-19 and the results might look different as more data is collected in future.

\section{CONCLUSIONS}

Nepali children with COVID-19 commonly present with asymptomatic or mildly symptomatic infection. Fever and respiratory symptoms are the most commonly reported symptoms in line with reports from elsewhere in the world. Most children do not develop complications as opposed to adult literature. Continued surveillance in larger population of children as the pandemic unfolds will generate more stringent observations. 


\section{REFERENCES}

1. Shereen MA, Khan S, Kazmi A, Bashir N, Siddique R. COVID-19 infection: Origin, transmission, andcharacteristics of human coronaviruses. J Adv Res. 2020 Mar 16;24: 91-98. doi:10.1016/j.jare.2020.03.005.

2. World Health Organization: Coronavirus updates Available at: https://www.who.int/docs/default-source/ coronaviruse/situation-reports/20201005-weekly-epi-update-8.pdf [Accessed 18 Oct 2020]

3. Bastola A, Sah R, Rodriguez-Morales AJ, Lal BK, Jha R, Ojha HC, et al. The first 2019 novel coronavirus case in Nepal. Lancet Infect Dis. 2020;20(3):279-280. doi: 10.1016/S1473-3099(20)30067-0.

4. Ministry of Health, Nepal. Coronavirus disease (COVID-19) outbreak updates \& resource materials Available at: https://heoc.mohp.gov.np/update-on-novel-corona-virus-covid-19[ Accessed 17 Oct 2020]

5. Tung Ho CL, Oligbu P, Ojubolamo O, Pervaiz M, Oligbu G. Clinical Characteristics of Children with COVID-19. AIMS Public Health. 2020;7(2):258-73. Doi:10.3934/publichealth.2020022.

6. World Health Organisation: Official update on Corona Virus; Available on: https://www.who.int/docs/defaultsource/coronaviruse/situation-reports/20201005-weekly-epi-update-8.pdf [Last Accessed 17 Oct 2020]

7. World Health Organisation. Clinical management of severe acute respiratory infection (SARI) when COVID-19 disease is suspected. Interim guidance. Pediatr. i Med. Rodz. 2020;16:9-26 .doi: 10.14740/jmc3515

8. Information on CoVID 19 Avaiable https://www.worldometers.info/coronavirus/[Last Accessed 17 Oct 2020].

9. Ministry of Health. DETAILED EPIDEMIOLOGICAL UPDATE COVID-19 - National and Provinces.Available at: http://edcd.gov.np/news/download/epidemiological-update-on-covid-19-11-aug-2020[Last accessed 15 Oct 2020]

10. Lee B, Raszka WV Jr. COVID-19 Transmission and Children: The Child Is Not to Blame. Pediatrics. 2020;146(2):e2020004879. Doi: 10.1542/peds.2020-004879.

11. Li J, Thoon K C, Chong C Y, Maiwald M, Tan NW. Comparative Analysis of Symptomatic and Asymptomatic SARS-CoV-2 Infection in Children. Ann Acad Med Singapore. 2020;49:530-537.

12. Oran DP, Topol EJ. Prevalence of Asymptomatic SARS-CoV-2 Infection. Ann Intern Med. 2020;173:362-7. doi: https://doi.org/10.7326/M20-3012

13. Meyers KJ, Jones ME, Goetz IA, Botros FT, Knorr J, Manner DH, et al. A cross-sectional community-based observational study of asymptomatic SARS-CoV-2 prevalence in the greater Indianapolis area. J Med Virol. 2020:10: 1-5. doi: 10.1002/jmv.26182

14. HeJ, Guo Y, Mao R, Zhang J. Proportion of asymptomatic coronavirus disease 2019: A systematic review and meta-analysis. J Med Virol. 2020;10:1-6. doi: 10.1002/jmv.26326.

15. Morand A, Fabre A, Minodier P, Boutin A, Vanel N, Bosdure E, et al. COVID-19 virus and children: What do we know? Arch Pédiatr. 2020;27(3):117-8. Doi:10.1016/j.arcped.2020.03.001.

16. Ludvigsson JF. Systematic review of COVID-19 in children shows milder cases and a better prognosis than adults. Acta Paediatr. 2020;109(6):1088-95. Doi:10.1111/apa.15270

17. Lingappan K, Karmouty-Quintana H, Davies J, Akkanti B, Harting MT. Understanding the age divide in COVID-19: why are children overwhelmingly spared? Am J Physiol Lung Cell Mol Physiol. 2020;319(1):39-44. doi:10.1152/ajplung.00183.2020

18. Ortolan A, Lorenzin M, Felicetti M, Doria A, Ramonda R. Does gender influence clinical expression and disease outcomes in COVID-19? A systematic review and meta-analysis. Int J Infect Dis. 2020;99:496-504. doi:10.1016/ j.ijid.2020.07.076

19. CDC COVID-19 Response Team. Coronavirus Disease 2019 in Children - United States, February 12-April 2, 2020. MMWR Morb Mortal Wkly Rep. 2020;69(14):422-6. doi: 10.15585/mmwr.mm6914e4.

20. Gaborieau L, Delestrain C, Bensaid P, Vizeneux A, Blanc P, Garraffo A, et al. Epidemiology and Clinical Presentation of Children Hospitalised with SARS-CoV-2 Infection in Suburbs of Paris. J Clin Med. 2020;9(7): 2227-9. doi:10.3390/jcm9072227.

21. Dong Y, Mo X, Hu Y, Qi X, Jiang F, Jiang Z, et al. Epidemiology of COVID-19 Among Children in China. Pediatrics. 2020;145(6):e20200702. doi: 10.1542/peds.2020-0702. 
22. Ding Y, Yan H, Guo W. Clinical Characteristics of Children With COVID-19: A Meta-Analysis. Front. Pediatr. 2020;8:431. doi: 10.3389/fped.2020.00431.

23. ShekerdemianL.S, Mahmood NR, Wolfe KK, Riggs BJ, Ross CE, Mckiernana CA, et al. Characteristics and Outcomes of Children With Coronavirus Disease 2019 (COVID-19) Infection Admitted to US and Canadian Pediatric Intensive Care Units. JAMA Pediatr. 2020;174(9):868-73. doi: 10.1001/jamapediatrics.2020.1948.

24. Hoang A, Chorath K, Moreira A, Evans M, Burmeister-Morton F, Burmeister F, et al. COVID-19 in 7780 pediatric patients: A systematic review. E Clinical Medicine. 2020;24:100433. doi:10.1016/j.eclinm.2020.100433.

25. World Health Organization. Multisystem inflammatory syndrome in children and adolescents with COVID-19. Published 2020 May 15.

26. Diorio C, Henrickson SE, Vella LA, McNerney KO, Chase J, Burudpakdee C, et al. Multisystem inflammatory syndrome in children and COVID-19 are distinct presentations of SARS-CoV-2. J Clin Invest. 2020:140970. Doi: 10.1172/JCI140970. 